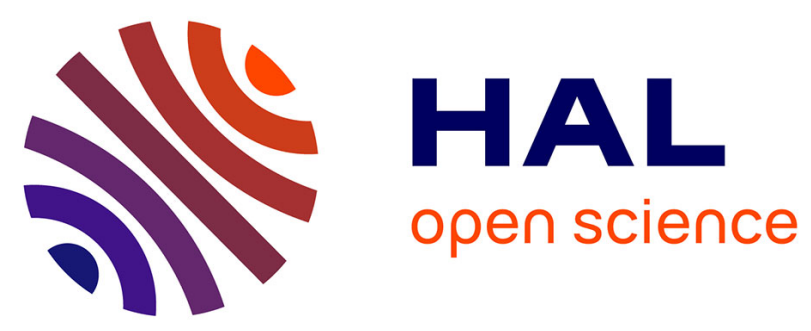

\title{
State of Charge and Thermal-Related Deterioration Prediction for Li-Ion Storage Systems in Hybrid Photovoltaic Systems in the Island of Corsica
}

Alberto Vazques-Rodriguez, François-Pascal Neirac, Georges Kariniotakis

\section{- To cite this version:}

Alberto Vazques-Rodriguez, François-Pascal Neirac, Georges Kariniotakis. State of Charge and Thermal-Related Deterioration Prediction for Li-Ion Storage Systems in Hybrid Photovoltaic Systems in the Island of Corsica. 26th International Conference \& Exhibition on Electricity Distribution (CIRED 2021), CIRED, Sep 2021, Virtual Event, Switzerland. hal-03407790

\author{
HAL Id: hal-03407790 \\ https://hal.science/hal-03407790
}

Submitted on 28 Oct 2021

HAL is a multi-disciplinary open access archive for the deposit and dissemination of scientific research documents, whether they are published or not. The documents may come from teaching and research institutions in France or abroad, or from public or private research centers.
L'archive ouverte pluridisciplinaire HAL, est destinée au dépôt et à la diffusion de documents scientifiques de niveau recherche, publiés ou non, émanant des établissements d'enseignement et de recherche français ou étrangers, des laboratoires publics ou privés. 


\title{
STATE OF CHARGE AND THERMAL-RELATED DETERIORATION PREDICTION FOR LI-ION STORAGE SYSTEMS IN HYBRID PHOTOVOLTAIC SYSTEMS IN THE ISLAND OF CORSICA Alberto Vazques-Rodriguez ${ }^{1,2^{*}}$, François-Pascal Neirac ${ }^{1}$, Georges Kariniotakis ${ }^{1}$
}

\author{
${ }^{I}$ MINES ParisTech, PSL University, Centre PERSEE, Sophia-Antipolis, France \\ ${ }^{2}$ SPIE Industrie \& Tertiaire - Division Industrie, SPIE France, Aix-en-Provence, France \\ *aevazquezr@gmail.com
}

\begin{abstract}
Keywords: LI-ION ENERGY STORAGE SYSTEM, PHOTOVOLTAIC, STATE OF CHARGE, MODELLING, ENERGY MANAGEMENT SYSTEM
\end{abstract}

\begin{abstract}
Today there is a high interest to install hybrid systems composed by renewable power plants (RES) coupled to energy storage systems (ESS) on geographical islands with or without interconnection. Such is the case in Corsica, an island system with a small interconnection to Italy. Given the objectives for high RES penetration, Corsica has been a playground for the deployment of new hybrid photovoltaic (PV) plants coupled to li-Ion based ESS. The introduction of this new technology imposed new challenges in management and operation of the ESS to guarantee the performance and profitability of such power plants. In this work, different estimation models were developed to predict the thermal behaviour and State of Charge (SoC) of 5 existing hybrid RES power plants that have a li-ion based storage. These approaches allowed a better understanding of the evolution and degradation the systems experience, insights that were later used to optimise the energy management systems present in each power plant.
\end{abstract}

\section{Introduction}

Solar and wind power technology's improvements, in junction with a strong political will to enact an energy transition into low-carbon solutions, have increased the penetration of renewable energy sources (RES) into the energy mix. RES, having as an advantage a low marginal cost per MWh, contribute to decrease the off-peak and peak power prices following the merit order criteria used in the European electricity grid. A merit order trend projection for RES in the next 10 and 30 years expects an average decrease of $1.6 € / \mathrm{MWh}$ for the former and $4.2 € / \mathrm{MWh}$ for the latter, being the less electrically interconnected regions that benefited the most from such integration [1]. With the increasing presence of RES in the energetic mix, the need for mechanisms to ensure the grid stability increases as well.

Nevertheless, the intrinsic variability of RES changes the paradigm of what is needed on current electrical grids and imply higher reserve requirements, factors resulting to "hidden" costs that need to be taken into account in the long run [2]. In the case of geographical islands, the impact from the intermittency of RES goes beyond cost as it also represents a source of instability. The French islands have famously had a cap of $30 \%$ of variable renewable energy they allow into the mix since 2008 to ensure stability and safe operation without the need of new infrastructures [3]. The French Commission for Energy Regulation (CRE) has acknowledged this limitation in past and current calls for tenders by building a capacity firming framework in which new hybrid systems composed by photovoltaic or wind power plants coupled to battery energy storage systems (BESS) can participate in the insular electricity production [4]. Several such hybrid systems have been deployed as consequence, often using li-ion based chemistry thanks to the increasingly cheaper technology and the more flexible range of operation in comparison to classic lead batteries [5].

The rules of operation of such systems are well defined as they should pre-announce and respect injection power profiles to avoid financial penalties. The high cost of storage devices, as well as the uniqueness of solar-dependent charge/discharge curves makes it necessary to understand the in-situ behaviour, constraints, and degradations of the battery systems. In general, the effects of the manufacturers' battery management system (BMS) in usage are mostly not considered. Even when they are, these limits are often constrained to reducing the operating State of Charge allowed [4]. Any more realistic or complex implementation of a BMS can rapidly evolve into discontinuities and thus complexity. Battery manufacturers usually provide a minimal output energy engagement from a battery device, but operators require detailed models for the devices that would allow a more accurate representation of the operation and thus a better estimation of the financial revenues during multi-annual operation to justify the investments. For residential BESS, an efficient usage and management has been 
shown to reduce maintenance costs or even allow the system to be profitable for operation [6], [7].

The objective of this paper is to showcase the real case of 4 hybrid MW-size PV/BESS plants in Corsica and to present the thermal, State of Charge (SoC) and State of Health (SoH) models developed for the BESS using real in-situ data. Such models are used to optimize the plant's operation and respect the imposed constraints by the capacity firming framework. The aim is to reduce modelling uncertainties of the storage behaviour and the impact this may have on penalties from deviations between predicted and scheduled power of the combined PV/EES plant.

\section{Methodology}

Despite the fact that each battery disposes its own embedded BMS by the manufacturer, we had to develop an energy management system (EMS) for the entire hybrid power plant designed specifically to respect the requirements imposed by the capacity firming framework for the hybrid (PV + BESS) power plants in the island of Corsica in France. Among the functions it executes are the real-time coordination on the different power orders sent to each equipment, and the supervision, management and storage of any measurement which is fundamental to the operation of the hybrid plant.

The developed EMS was then deployed into 5 different sites where hybrid power plants have been installed: a proof-ofconcept (POC) site in continental France, and 4 full-sized operating hybrid power plants in Corsica.

\subsection{BESS data acquisition procedure}

All sites where the 5 hybrid power plants are installed share a common electrical structure as seen in Fig. 1 The data sources contain two types of data acquisition points, analogue measurements of electrical values and digital data that are obtained by each of the two main elements of the hybrid plant (PV plant or BESS) using their own internal data acquisition mechanisms. Analogue measurements are agnostic to the sites, but any storage related information is dependent on the battery constructor. Below we give more detailed information for each site:

2.1.1 POC site: this site is composed of three $3.3 \mathrm{~kW} / 6.5 \mathrm{kWh}$ li-ion battery blocks with their respective inverter.

The information available are the DC current, voltage, battery temperature and SoC as measured by the embedded monitoring of the BESS manufacturer. The analogue measurements are the AC power and the external ambient temperature.

2.1.2 Corsica's sites: the BESS in each site is composed of multiple battery-only cabinets and multiple DC/AC converters. Nevertheless, only system-wide measurements are available, and the BESS is treated as a singular unit. The nominal capacities are shown in Table 1. Any information specific to a singular inverter or battery block is not published by the manufacturer.

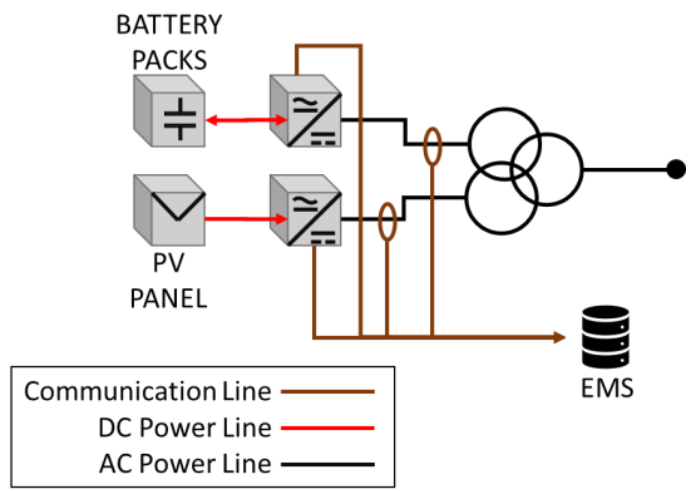

Fig. 1 Classic electrical power scheme for hybrid PV/BESS power sites in Corsica. The power transfer between the BESS and the PV system is done through the AC grid.

The information available are the SoC, energy available for discharge and maximal energy of the system at full charge. The analogue measurements are the AC power and two temperatures measurements, one for the ambient air and the second for the battery pack's cabinet surface.

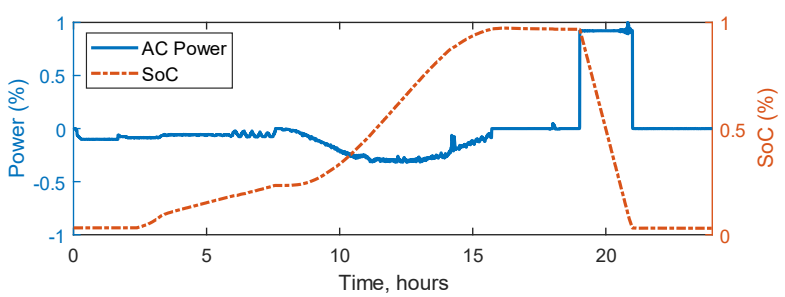

(a)

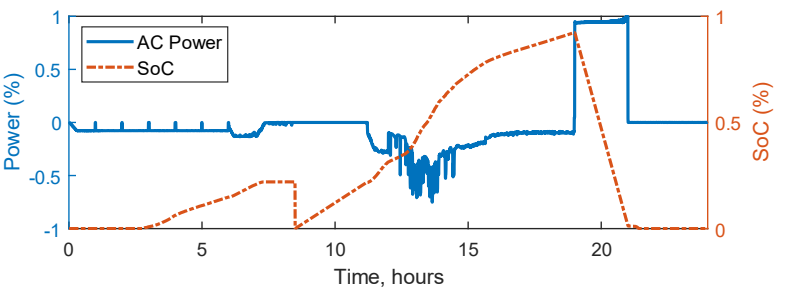

(b)

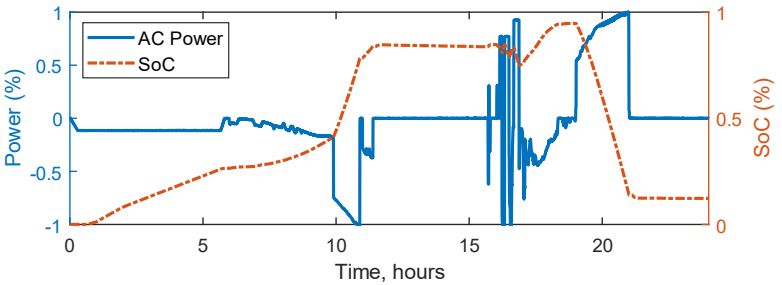

(c)

Fig. 2 Power (straight line) and SoC (dotted line) curves from different days. Subfigure (a) is from a day accepted by the data treatment. Subfigures (b) and (c) are examples of rejected days because of intermittent disconnection of the ESS or because of an abnormal operation.

In all sites, the key information was stored as instantaneous values with a frequency of $1 \mathrm{~Hz}$. However, this temporal 
resolution is not used systematically. All the data treatment and models were done using instantaneous values with an interval of 20 s.

\subsection{BESS data treatment}

Three types of phenomena that can alter the quality of the data were detected since the commissioning of the sites: missing/fake datapoints, abnormal power production due to errors or manual mismanagement, and electrical outages. A numerical and visual filter were used to retain the days that best expose the nominal operation of hybrid sites in Corsica. Fig. 2 shows a clean curve from an accepted day, as well as curves from days not accepted for further analysis.

An additional variable representing the time in years since the power plant's BESS started to be in nominal operation was also added.

Table 1 BEES power and energy storage characteristics for the sites in Corsica

\begin{tabular}{lll}
\hline Site & Nominal Power & Nominal Energy \\
\hline Site A & $980 \mathrm{kVA}$ & $1218 \mathrm{kWh}$ \\
Site B & $1560 \mathrm{kVA}$ & $2028 \mathrm{kWh}$ \\
Site C & $1610 \mathrm{kVA}$ & $2088 \mathrm{kWh}$ \\
Site D & $2030 \mathrm{kVA}$ & $2610 \mathrm{kWh}$ \\
\hline
\end{tabular}

\subsection{BESS internal temperature estimation model}

This section describes the modelling process for the BESS internal temperature. This is important because it's been demonstrated that operation in extreme temperatures can create irreversible chemical processes that impact the performance of the BESS as lithium-plating and, more impactful on human safety, a thermal runaway [8], [9] The thermal models that we considered are based on three measurements to estimate the battery's temperature: the SoC, the external ambient temperature and the DC current. Two different estimation approaches were used: an intra-day temporal estimation and a minimum/maximum temperature approach. The former was done using a classical heat equation approach seen in eq. (1) where the first element represents the heat generated by the battery's operation, and the second term represents the thermal external exchanges due to convection [10], [11]. For the former model, we used a neural network, where only the daily discharge throughput and the average external temperature per day was given as inputs for the model.

$$
\frac{d T}{d t}=\frac{R_{\text {int }}}{C_{p}} I^{2}(t)+\lambda\left(T_{\text {ext }}(t)-T_{\text {bat }}(t)\right)
$$

In equation (1), the specific heat $C_{p}$ and the heat transfer coefficient $\lambda$ depend exclusively on the materials and physical configuration. In contrast, the internal resistance $R_{\text {int }}$ is an indicator for the internal state of the battery's chemistry. A parameter identification was done on such parameters by using exclusively the data of the POC site. Given the unavailability of battery pack temperature, any validation of parameters is impossible in the other sites.

\subsection{The SoC estimation model}

The state of charge estimation model was developed by using power data series and an equivalence of a classical coulomb counter written in terms of power.[12] The initial first order model of equation (2) was applied. It uses an energy efficiency coefficient $\eta$ as published by the battery manufacturer.

$$
\operatorname{SoC}(t)=\operatorname{SoC}\left(t_{0}\right)-\int \frac{\eta P(t)}{C_{k W h}} d t
$$

By using the real in-situ data of the BESS's power flux, and the constructor's own SoC estimation, new efficiency coefficients were calculated.

\subsection{BESS deterioration's evolution}

Both the internal resistance and the energy efficiency coefficient previously mentioned reflect the health of the battery cells [12]: A higher internal resistance reflects a chemistry deterioration and lowers the capacity of the battery cells in a BESS [13], while it's been reported in commercial battery cells how the round trip efficiency at the End-of-Life (EoL, usually defined at $80 \%$ capacity) of the batteries shows a decrease of at least 5\% [14]. To monitor the deterioration, the internal resistance was estimated in a daily basis to observe its evolution in time.

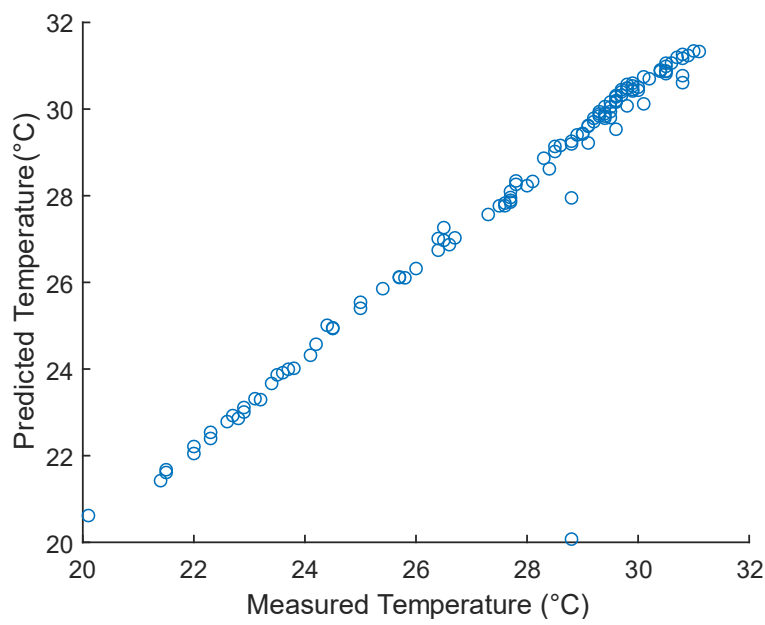

Fig. 3 Expected temperature (y-axis) vs real temperature (xaxis) using a neural network max. temperature predictor with three hidden layers.

\section{Evaluation results}

The nominal site's power operation relies heavily on the estimated values for SoC to decide what amount of the 
photovoltaic production is sent to the BESS. Any correction and improvement on this estimation allows the EMS to make better decisions. Unwanted phenomena and deviations from the planned power production were reduced to a greater extent after applying newly calculated performance coefficients. To analyze the different results from the models, the RMSE between the expected and real values was used systematically.

\subsection{Temperature estimation}

The neural network used to predict the min/max temperature of the battery packs showed an average error of less than $1^{\circ} \mathrm{C}$ for the three ESS from the POC site. Different number of hidden layers in the neural network were used but no significant improvement could be detected by modifying this parameter from the base value of three.

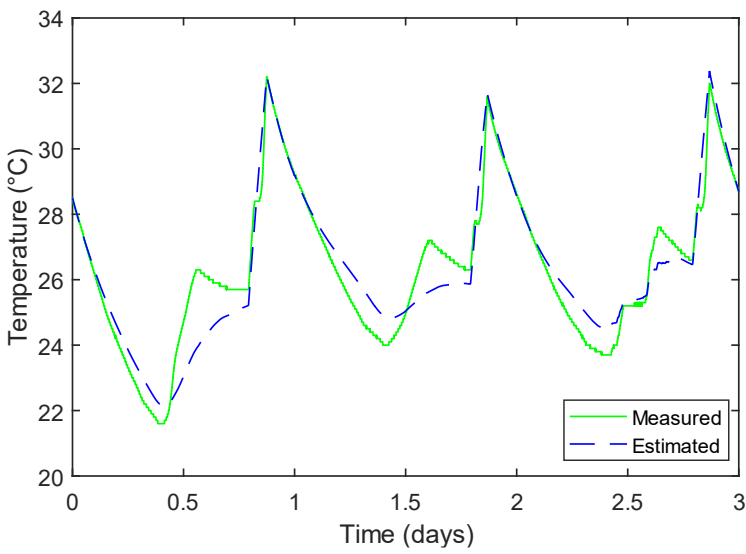

Fig. 4 Temperature measurements from an ESS in the PoC site. The green line (solid) represents the real temperature as reported by the BMS, and the blue line (sectioned) represents the estimated value.

Table 2 Average daily RMSE in ${ }^{\circ} \mathrm{C}$ for temperature predictions.

\begin{tabular}{ccc}
\hline PoC's ESS & $\begin{array}{c}\text { 3 Hidden Layers } \\
\text { Max. Temp }\end{array}$ & Intra-day \\
\hline$\# 1$ & 0.926 & 1.434 \\
$\# 2$ & 0.948 & 0.992 \\
$\# 3$ & 0.951 & 0.727 \\
\hline
\end{tabular}

Regarding the intra-day prediction in Fig. 4, it showed to be less efficient in maximal temperature prediction with an RMSE $>1{ }^{\circ} \mathrm{C}$ although it followed the real temperature's behavior. The instantaneous RMSE values for these BESS were between $0.7^{\circ} \mathrm{C}$ and $1.4^{\circ} \mathrm{C}$. Table 2 summarizes the errors found for these two approaches.

\subsection{SoC estimation}

The power counter using the roundtrip performance as given by the ESS constructor had an average RMSE of 10\%. By itself, the SoC prediction allowed the operating EMS to correct the in-situ deviations due to the real performance disparity. However, as it can be seen in the first hours of operation in Fig. 5, disparities between the expected and real SoC due to non-linearities induced by the manufacturer's integrated BMS generate undesirable behavior in the charge-discharge curves.

The new efficiency parameters calculated using operation conditions data reduced the RMSE to $4 \%$, and certain nonlinearities due to unreliable information by the BMS could be circumvented.

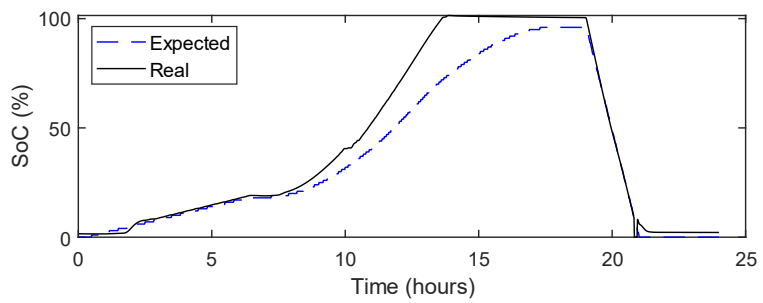

(a)

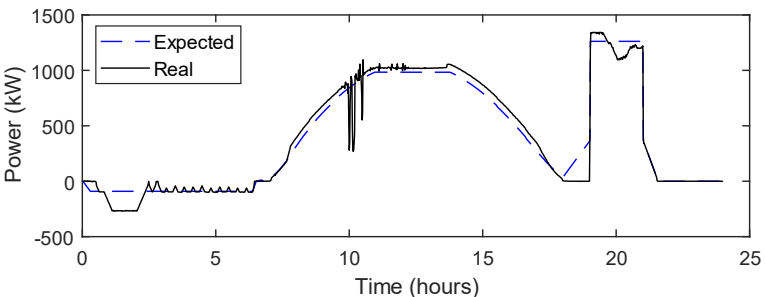

(b)

Fig. 5 Real SoC and power production an operating site. Subfigure (a) shows the initially estimated SoC and the real value as reported by the BMS. Subfigure (b) shows the planned power production and the real output power.

\subsection{Battery degradation}

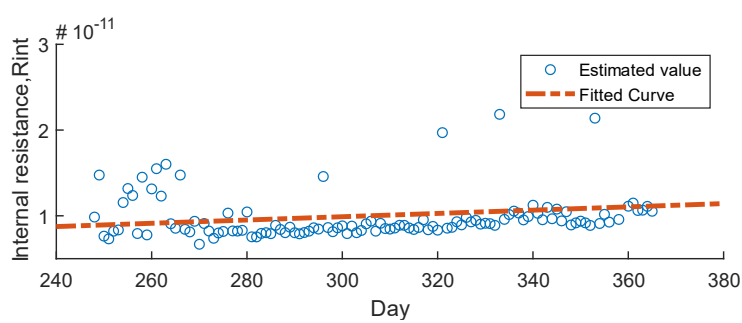

(a)

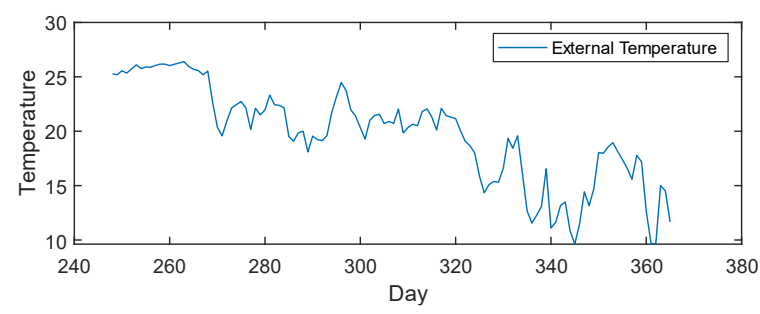

(b)

Fig. 6 Estimated internal resistance's parameter in the heat equation. Subfigure (a) shows the trend in a daily basis. Subfigure (2) shows the temperature for the respective days. 
The internal resistance parameter was calculated per day using the thermal model. The results, as seen in Fig. 6 demonstrate an increasing value trend. This finding is coherent with the expected temporal degradation li-ion batteries experience as the internal chemistry degrades. The linear trend did not show a significant increase with the lower external temperature.

\section{Conclusion}

Two different models were used to analyse the performance and evolution of li-Ion BESS in hybrid photovoltaic sites operating under the capacity firming framework defined by CRE in France. These sites respect specific constraints in terms of engagements to the grid manager and imply a distinctive charge/discharge profile as well.

The thermal model was able to predict within 1 degree Celsius the temperature of the battery packs. No significant benefit between an intra-day prediction and the $\mathrm{min} / \mathrm{max}$ predictor was found, but the insight gained from the increase and trend in internal resistance could make the foundation for more complex EoF analyses.

The initial state of charge estimation deployed was shown to be effective by itself; The $10 \%$ error it showed initially, although minimised in further calculations of the performance parameter, did not show any significant loss in revenue for the 4 sites in Corsica. The large margins of errors accepted by the grid manager to manoeuvre any solar variability are exploited in the EMS and the effect of an inaccurate SoC prediction are reduced. A smaller accepted deviation from he planned power productions would put more strain on the accuracy of the battery model.

Future works will focus on implementing the knowledge gained from the thermal battery model into long-term SoC and SoH predictions for large-scale BESS. Given that some battery constructors do not make available all the battery-related information, including thermal measurements, the models must be able to consider these phenomena without à direct estimation due to the impossibility to corroborate it.

\section{Acknowledgements}

This work was supported by SPIE Industrie et Tertiaire and in part by a $\mathrm{PhD}$ grant by ANRT (Association National Recherche Technologie).

\section{References}

[1] P. Deane, S. Collins, B. Ó. Gallachoir, et al., "Quantifying the merit-order effect in European electricity markets"(Insight Energy, 2015), pp 1-6

[2] P. Heptonstall, R. Gross, and F. Steiner, "The costs and impacts of intermittency - 2016 update: A systematic review of the evidence on the costs and impacts of intermittent electricity generation technologies" (UKERC, 2017)
[3] Cour des comptes, "La politique de développement des énergies renouvelables,"( La documentation Française, 2013), pp 220-241

[4] CRE, "Appel d'offres portant sur la réalisation et l'exploitation d'installations de production d'électricité à partir de techniques de conversion du rayonnement solaire d'une puissance supérieure à $100 \mathrm{kWc}$ et situées dans les zones non interconnectées," (2015)

[5] M. T. Lawder et al., "Battery Energy Storage System (BESS) and Battery Management System (BMS) for GridScale Applications," Proc. IEEE, vol. 102, no. 6, pp. 1014 1030

[6] C. A. Correa-Florez, A. Gerossier, A. Michiorri, et al., "Stochastic operation of home energy management systems including battery cycling," Appl. Energy, 2018, vol. 225, pp. 1205-1218

[7] M. Naumann, R. C. Karl, C. N. Truong, et al., "Lithiumion Battery Cost Analysis in PV-household Application," Energy Procedia, 2015, vol. 73, pp. 37-47

[8] T. M. Bandhauer, S. Garimella, and T. F. Fuller, "A Critical Review of Thermal Issues in Lithium-Ion Batteries," J. Electrochem. Soc., 2011

[9] N. Legrand, B. Knosp, P. Desprez, et al., , "Physical characterization of the charging process of a Li-ion battery and prediction of Li plating by electrochemical modelling," J. Power Sources, 2014 vol. 245, pp. 208-216

[10] S. C. Chen, C. C. Wan, and Y. Y. Wang, "Thermal analysis of lithium-ion batteries," J. Power Sources, 2005, vol. 140 , no. 1 , pp. $111-124$

[11] D. Roberts, P. Taylor, and A. Michiorri, "Dynamic thermal rating for increasing network capacity and delaying network reinforcements," in CIRED Seminar 2008: SmartGrids for Distribution, 2008, pp. 61-61

[12] Z. Miao, L. Xu, V. R. Disfani, et al., "An SOC-Based Battery Management System for Microgrids," IEEE Transactions on Smart Grid, 2014, vol. 5, no. 2. pp. 966-973

[13] D. Ansean, M. Gonzalez, J. C. Viera, et al., "Electric Vehicle Li-Ion Battery Evaluation Based on Internal Resistance Analysis,", IEEE Vehicle Power and Propulsion Conference (VPPC), Oct. 2014, pp. 1-6

[14] Y. Preger, H. M. Barkholtz, A. Fresquez, et al., "Degradation of Commercial Lithium-Ion Cells as a Function of Chemistry and Cycling Conditions," J. Electrochem. Soc., 2020, vol. 167 , no. 12 